\title{
Evaluation of Combined Transcathter Arterial Chemo Embolization (TACE) with Percutaneous Ethanol Injection (PEI) Vs. (TACE) for Unresectable Hepatocellular Carcinoma
}

\author{
Heba Samier ${ }^{1, *}$, Hazem Omar ${ }^{2}$, Rasha Dawoud ${ }^{1}$, Alsiagy Ali Salama ${ }^{1}$, Abd-Elmonem Nooman ${ }^{1}$ \\ ${ }^{1}$ Department of Radiology, Faculty of Medicine, Tanta University, Tanta, Egypt \\ ${ }^{2}$ National Liver Institute, Menoufia University, Menoufia, Egypt \\ Email address: \\ heba.samier21@yahoo.com (Heba S.), hazemomar2020@gmail.com (Hazem O.), Roshy dawoud@yahoo.com (Rasha D.) \\ Siagyali33@yahoo.com (Alsiagy A. S.), Abdelmonem_nooman@med.tanta.edu.eg (Abd-Elmonem N.) \\ ${ }^{*}$ Corresponding author
}

\section{To cite this article:}

Heba Samier, Hazem Omar, Rasha Dawoud, Alsiagy Ali Salama, Abd-Elmonem Nooman. Evaluation of Combined Transcathter Arterial Chemo Embolization (TACE) with Percutaneous Ethanol Injection (PEI) Vs. (TACE) for Unresectable Hepatocellular Carcinoma. International Journal of Medical Imaging. Vol. 8, No. 3, 2020, pp. 54-64. doi: 10.11648/j.ijmi.20200803.14

Received: September 19, 2020; Accepted: October 5, 2020; Published: October 12, 2020

\begin{abstract}
There are many treatment options available for hepatocellular carcinoma (HCC) but the best choices for intermediate and advanced tumors are sometimes a matter of controversies. The aim of the work was to compare the combined Trans-catheter arterial chemoembolization (TACE) with percutaneous ethanol injection (PEI) against the technique of TACE alone in patients with unresectable HCC. The study included fifty patients proved radiologically to have hepatocellular carcinoma $(\mathrm{HCC})>5 \mathrm{~cm}$ in diameter and were not candidate for surgical resection. The patients were divided into two groups Group 1: Patients underwent single Trans-catheter arterial chemoembolization (TACE) followed by four times of Percutaneous ethanol injection (PEI) every other day. Group 2: Patients underwent repeated Trans-catheter arterial chemoembolization (the frequency of sessions was according to response of the patients). Complete resolution of HCC masses achieved in $60 \%$ in group 1 versus $52 \%$ in group 2. This complete resolution occurred earlier in group 1 than group 2 . Group 1 had lower local recurrence rate than group 2. There was a statistically significant reduction in alpha-feto protein level at 3 months post interventional in group 1 and in both groups at 6 months. There was no significant difference between both groups in overall survival, So combined treatment could help in saving time and resources.
\end{abstract}

Keywords: Trans-catheter Arterial Chemoembolization, Percutaneous Ethanol, HCC

\section{Introduction}

HCC is the sixth most common cancer in the world currently [1] with most of patients diagnosed at intermediate or advanced stages [2-4], 30\% of patients with early-stage may get benefit from curative therapies, such as surgical resection and liver transplantation [5,6]. But, for patients with large lesions or liver dysfunction, surgical resection is not recommend as the first-treatment choice whereas the palliative care, including transcatheter arterial chemoembolization (TACE) and percutaneous ethanol injection (PEI), are widely used [2].
Repeated intra-arterial injections of a chemotherapeutic agent such as cisplatin, doxorubicin, or mitomycin $\mathrm{C}$ mixed with lipiodol is the standard protocol adopted in many institutions [7].

TACE has been proved to prolong the survival in intermediate-stage HCC patients, especially for those with large and multiple lesions [2]. And, PEI as a thermal in situ destruction technique has been shown to be more effective in the treatment of small HCC patients $[8,9]$.

Accumulating evidence suggests that combined treatment of TACE and PEI may play a synergistic effect in HCC patients, especially for larger lesions that do not respond adequately to either procedure alone [10]. 


\section{Patients and Methods}

This prospective interventional study was conducted on 50 patients proved radiologically to have hepatocellular carcinoma (HCC) $>5 \mathrm{~cm}$ in diameter and were not candidate for surgical resection.

Cases were referred to Radiology Department, National Liver Institute- Monofya University and Radiodaignosis department- Tanta University, Our study duration was two years from February 2017 to February 2019.

\subsection{Inclusion Criteria}

1) Presence of an unresectable hepatocellular carcinoma.

2) Single $\mathrm{HCC}>5 \mathrm{~cm}$

3) Patent main portal vein and its branches.

4) Patients with Child-Pugh classification A or early B.

5) Satisfactory liver and renal functions.

\subsection{Exclusion Criteria}

1) Age older than 80 years and younger than 18 years.

2) Evidence of extra hepatic metastases.

3) Complete portal vein thrombosis (main trunk or both branches).

4) Patients with severe hemodynamic instability.

5) Patients with serous coagulation disorder (platelet counts $<50000 / \mu \mathrm{L}$, prothrombin activity $<50 \%$ ) or an acute sepsis.

The patients were divided into two groups

Group 1: Patients underwent single Trans-catheter arterial chemoembolization (TACE) followed by four times Percutaneous ethanol injection (PEI) every other day.

Group 2: Patients underwent repeated Trans-catheter arterial chemoembolization (TACE) (the frequency of sessions was according to response of the patients).

\subsection{Technique}

\subsubsection{Transcatheter Arterial Chemoembolization}

i- Chemoembolization was performed percutaneously in the angiography suite, after infiltration of local anesthetic.

ii- The Seldinger technique was used to gain access to the common femoral artery through femoral artery puncture. A 5 -French vascular sheath was placed into the common femoral artery over a 0.035-inch Guide-wire. Under fluoroscopic guidance, 5-French Cobra head catheter was advanced over the guide-wire into the descending abdominal aorta, and then used to select the celiac axis. Celiac arteriogram was done to assess the anatomical distribution of the celiac trunk and to exclude the presence of any possible anatomical variations.

iii- Screening began with injection of $20 \mathrm{cc}$ contrast medium over about $20 \mathrm{sec}$. Then hepatic artery arteriogram was done to determine the arterial anatomy and the angiographic mapping of the lesion then the catheter was advanced into the desired hepatic artery branch, depending on the tumor location which marked and identified by the arterial blush. iv-10ml Lipiodol mixed with $50 \mathrm{mg}$ adriamycin were slowly injected over 3 minutes through the catheter under

fluoroscopic control. The gelfoam particles were added in twenty three patients in whom superselective catheterization was done. The particles were mixed with the contrast media (10ml urographin) and were injected when the mixture appeared homogenous.

$\mathrm{v}$-The catheter and introducer sheath were withdrawn and good compression of the puncture site was maintained for 10 to 15 minutes.

\subsubsection{Percutaneous Ethanol Injection (PEI)}

i-Thorough skin disinfection.

ii-local anesthesia was done by using $10 \mathrm{ml}$ of $2 \%$ xylocaine to anesthetize the skin, subcutaneous tissue, muscles and liver capsule along the assumed track of entry.

iii- A pre-incision of the skin was done then absolute sterile ethanol $(96 \%)$ was slowly injected trans-cutaneous into the tumor using a $18 \mathrm{G}$ Chiba needles under real-time ultrasound guidance using a $3.5-\mathrm{MHz}$ convex probe with a lateral guide attachment, The needle inserted to the deep portion of the tumor and Ethanol $(96 \%$ vol.) was continuously injected in an amount calculated by equation $(\mathrm{V}$ $=4 / 3 \pi[(D / 2) 3])$ where's: $\mathrm{V}$ is the volume in milliliters and $\mathrm{D}$ is the largest tumor dimension in centimeter or injection was finished when resistance was felt or escape of ethanol beyond the tumor was seen on US.

\subsection{Evaluation of Response}

It was done after 1, 3 and 6 months by triphasic CT scan of the liver to identify tumor size, distribution of the lipidol within the entire mass and surrounding target segment, and local or remote recurrence. Alpha-feto protein levels were also assessed.

\section{Results}

Our study included 50 patients with unresectable HCC. The mean age of our patients was $64.16 \pm 7.32,46$ patients representing $92 \%$ were males versus 4 patients representing $8 \%$ were females.

Regarding clinical presentation, $54 \%$ presented with abdominal pain, $30 \%$ by weight loss and $16 \%$ was accidentally discovered.

As regard to Child class $31(62 \%)$ patients were Child A class versus 19 (38\%) patients Child B class

Comparison between both group as regard to Child class was statistically non significant.

Among our 50 patients: Group 1 had 3 patients with left lobe mass (all at segment IV) and 22 patients with right lobe mass (13 of them at segment VII, 8 at segment V and one of them at segment VIII) while Group 2 had 6 patients with left lobe mass (four of them at segment III and two at segment II) and 19 at right lobe (6 of them at segment VIII, 5 at segment VI, 4 at segment VII, 3 at segment V and one at segments VI and VII).

So segments VII and VIII were the most common segments of HCC mass. 
Table 1. Alpha feto protein levels before and after intervention treatment.

\begin{tabular}{|c|c|c|c|c|c|c|c|c|c|c|}
\hline \multirow{3}{*}{ Alpha feto protein } & \multirow{2}{*}{\multicolumn{2}{|c|}{ Before }} & \multicolumn{6}{|l|}{ After } & \multirow{3}{*}{$\chi^{2}$} & \multirow{3}{*}{$\mathbf{P}$} \\
\hline & & & \multicolumn{2}{|l|}{ 1month } & \multicolumn{2}{|c|}{ 3months } & \multicolumn{2}{|l|}{ 6months } & & \\
\hline & No. & $\%$ & No. & $\%$ & No. & $\%$ & No. & $\%$ & & \\
\hline Group1 & $(n=25)$ & & $(n=22)$ & & $(n=22)$ & & $(n=21)$ & & & \\
\hline$<100$ & 8 & 32.0 & 11 & 50.0 & 15 & 68.2 & 15 & 71.4 & & \\
\hline $100-200$ & 1 & 4.0 & 2 & 9.1 & 4 & 18.2 & 5 & 23.8 & 23.938 & $0.0005^{*}$ \\
\hline$>200$ & 16 & 64.0 & 9 & 40.9 & 3 & 13.6 & 1 & 4.8 & & \\
\hline$\chi^{2}$ & & & 2.586 & & 12.685 & & 17.819 & & & \\
\hline$\stackrel{0}{\mathrm{P}}$ & & & 0.2744 & & $0.0018^{*}$ & & $0.0001 *$ & & & \\
\hline Group2 & $(n=25)$ & & $(n=23)$ & & $(n=21)$ & & $(n=19)$ & & & \\
\hline$<100$ & 8 & 32.0 & 8 & 34.8 & 8 & 38.1 & 11 & 57.9 & & \\
\hline $100-200$ & 2 & 8.0 & 2 & 8.7 & 1 & 4.8 & 1 & 5.3 & 3.751 & 0.7103 \\
\hline$>200$ & 15 & 60.0 & 13 & 56.5 & 12 & 57.1 & 7 & 36.8 & & \\
\hline$\chi^{2}$ & & & 0.060 & & 0.321 & & 2.953 & & & \\
\hline $\mathrm{P}$ & & & 0.9706 & & 0.8516 & & 0.2285 & & & \\
\hline
\end{tabular}

$\chi^{2}, \mathrm{p}: \chi^{2}$ and $\mathrm{p}$ values for Chi square test

*: Statistically significant at $\mathrm{p} \leq 0.05$

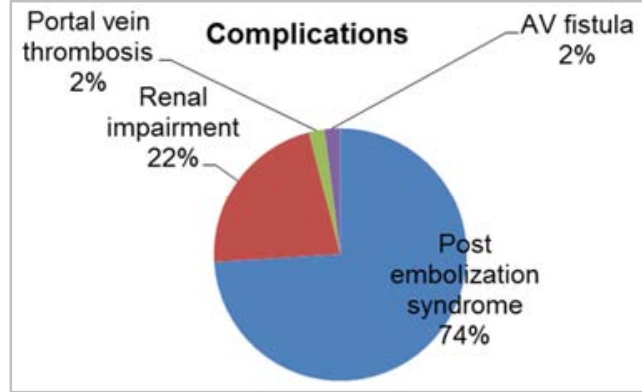

Figure 1. Complications after procedures.

Post embolization syndrome (fever, nausea, vomiting, anorexia and right hypochondrial pain) was the most common complication observed in about $37(74 \%)$ of the patients in the two studied groups. Portal vein thrombosis was observed in one patient in group 1 following the third session of alcohol injection so he was excluded from the statistical analysis (Figure 1).

Table 2. Response to intervention treatment in the two studied groups after the first session.

\begin{tabular}{llllll}
\hline \multirow{2}{*}{ Response } & \multicolumn{2}{l}{ Group 1 $(\mathbf{n = 2 3})$} & \multicolumn{2}{l}{ Group 2 $(\mathbf{n = 2 3})$} & $\boldsymbol{\chi}^{2} \mathbf{P}$ \\
\cline { 2 - 6 } & No & $\mathbf{\%}$ & No & $\mathbf{\%}$ & \\
\hline Complete & 16 & $69.56 \%$ & 3 & $13.04 \%$ & 15.154 \\
Incomplete & 7 & $30.4 \%$ & 20 & $86.95 \%$ & $0.0001 *$ \\
Total & 23 & $100 \%$ & 23 & $100 \%$ & \\
\hline
\end{tabular}

$\chi^{2}, \mathrm{p}: \chi^{2}$ and $\mathrm{p}$ values for Chi square test

*: Statistically significant at $\mathrm{p} \leq 0.05$
At one month follow up 16 patients of group 1 presenting about $69 \%$ showed complete response with total resolution of the mass activity versus only 3 patients in group 2 . Twenty patients representing about $87 \%$ still show residual activity within the mass in group 2 versus 7 patients in group 1. One patient died in group one after completing his alcohol sessions, another one underwent portal vein thrombosis after the third alcohol session and Was referred for systemic therapy. Two patients died in group 2 after the first TACE session (table 2)

Table 3. Recurrence and metastasis of HCC in the two studied groups.

\begin{tabular}{llllll}
\hline \multirow{2}{*}{ Recurrence } & \multicolumn{2}{l}{ Group 1 } & \multicolumn{2}{l}{ Group 2 } \\
\cline { 2 - 6 } & No & \% & No & \% \\
\hline \multicolumn{2}{l}{ Local recurrence (residual activity) } & 6 & $26.08 \%$ & 8 & $34.7 \%$ \\
Distant & Intrahepatic (other & 3 & $13.04 \%$ & 1 & $4.34 \%$ \\
recurrence & segment recurrence) & & & & $4.34 \%$ \\
Local and distant recurrence & 0 & $0 \%$ & 1 & 1 & $4.34 \%$ \\
\multicolumn{2}{l}{ Total } & 0 & $0 \%$ & 11 & $52.17 \%$ \\
\hline
\end{tabular}

At the end of 6 months follow up 6 patient of group 1 representing about $26 \%$ still show residual activity within the HCC mass versus 8 patients in group 2 representing about $34.7 \%$.

Three patients of group 1 showed other segment recurrence of hepatic focal lesions, no extrahepatic metastasis was recorded in this group versus two patients of suprarenal metastasis in group 2(table 3)

Table 4. Time and management of local and distant recurrence in the two studied groups.

\begin{tabular}{|c|c|c|c|c|c|c|c|c|c|c|c|c|}
\hline \multirow{3}{*}{$\begin{array}{l}\text { Time of } \\
\text { recurrence }\end{array}$} & \multicolumn{6}{|c|}{ Local recurrence } & \multicolumn{6}{|c|}{ Distant recurrence } \\
\hline & \multicolumn{3}{|c|}{ Group 1 (n=23) } & \multicolumn{3}{|c|}{ Group $2(n=23)$} & \multicolumn{3}{|c|}{ Group $1(n=23)$} & \multicolumn{3}{|c|}{ Group $2(n=23)$} \\
\hline & No & $\%$ & $\begin{array}{l}\text { Management } \\
\text { (TACE) }\end{array}$ & No & $\%$ & $\begin{array}{l}\text { Management } \\
\text { (TACE) }\end{array}$ & No & $\%$ & $\begin{array}{l}\text { Management } \\
\text { (TACE) }\end{array}$ & No & $\%$ & $\begin{array}{l}\text { Management } \\
\text { (TACE) }\end{array}$ \\
\hline 1 Month & 7 & $30.4 \%$ & 7 & 20 & $86.95 \%$ & 20 & 0 & $0 \%$ & 0 & 0 & $0 \%$ & 0 \\
\hline 3 Months & 9 & $39 \%$ & 9 & 15 & $65.21 \%$ & 15 & 1 & $4.34 \%$ & 1 & 0 & $0 \%$ & 0 \\
\hline 6 Months & 6 & $26 \%$ & 6 & 8 & $34.7 \%$ & 8 & 3 & $13.04 \%$ & 3 & 1 & $4.34 \%$ & 1 \\
\hline
\end{tabular}

At one month follow up 7 patients of group 1 show residual activity within the mass, they underwent TACE 
session, 2 of them showed total resolution of the mass at one, three and six months follow up. Four new patients showed local recurrence within the mass at three months follow up, they underwent TACE and 6 of them show total resolution of the mass on subsequent follow up. Another three new patients showed local recurrence within the mass at six months follow up with a total result of six patients showed residual activity at six months follow up and 14 patients showed total resolution of the mass activity among whom there were 7 patients with stationary course of total resolution at one, three and six months follow up needing for no extra sessions of TACE. As regard to group 2, 20 patients showed residual activity within the mass reduced to 8 patients at six months follow up with repeating TACE sessions, resulting in 12 patients with total resolution of mass activity at six months follow up (Table 4)

At three months follow up one patient of group 1 showed other segment recurrence together with local recurrence within the mass, underwent one session of TACE with total resolution of the mass in the next follow and residual activity within the newly developed lesion. Another two patients with other segments recurrence at six months follow up in group 1 versus one patient in group 2 (Table 4 ).

Table 5. The survival of patients in relation to Child-Pough classification and tumor size in the two studied groups.

\begin{tabular}{|c|c|c|c|c|c|c|c|c|c|c|c|c|}
\hline \multirow{4}{*}{$\begin{array}{l}\text { Item } \\
\text { Child- Pough class }\end{array}$} & \multicolumn{12}{|c|}{ Mortality } \\
\hline & \multicolumn{6}{|c|}{ Group 1} & \multicolumn{6}{|c|}{ Group 2} \\
\hline & \multicolumn{2}{|c|}{ Alive } & \multicolumn{2}{|c|}{ Died } & \multicolumn{2}{|c|}{ Total } & \multicolumn{2}{|c|}{ Alive } & \multicolumn{2}{|c|}{ Died } & \multicolumn{2}{|c|}{ Total } \\
\hline & No & $\%$ & No & $\%$ & NO & $\%$ & No & $\%$ & No & $\%$ & No & $\%$ \\
\hline Child A & 16 & $64 \%$ & 0 & $0 \%$ & 16 & $64 \%$ & 15 & $60 \%$ & 0 & $0 \%$ & 15 & $60 \%$ \\
\hline Child B & 8 & $32 \%$ & 1 & $4 \%$ & 9 & $36 \%$ & 8 & $32 \%$ & 2 & $8 \%$ & 10 & $40 \%$ \\
\hline Total & 24 & $96 \%$ & 1 & $4 \%$ & 25 & $100 \%$ & 23 & $92 \%$ & 2 & $8 \%$ & 25 & $100 \%$ \\
\hline \multicolumn{13}{|l|}{ Size of the lesion } \\
\hline$>7 \mathrm{~cm}-9 \mathrm{~cm}$ & 3 & $12 \%$ & 0 & $0 \%$ & 3 & $12 \%$ & 5 & $20 \%$ & 1 & $4 \%$ & 6 & $24 \%$ \\
\hline$>9 \mathrm{~cm}$ & 0 & $0 \%$ & 0 & $0 \%$ & 0 & $0 \%$ & 0 & $0 \%$ & 1 & $4 \%$ & 1 & $4 \%$ \\
\hline Total & 24 & $96 \%$ & 1 & $4 \%$ & 25 & $100 \%$ & 23 & $92 \%$ & 2 & $8 \%$ & 25 & $100 \%$ \\
\hline
\end{tabular}

\section{Cases}

\subsection{Case 1}

Clinical picture:

Male patient aged 68 years old presented by right hypochondial pain
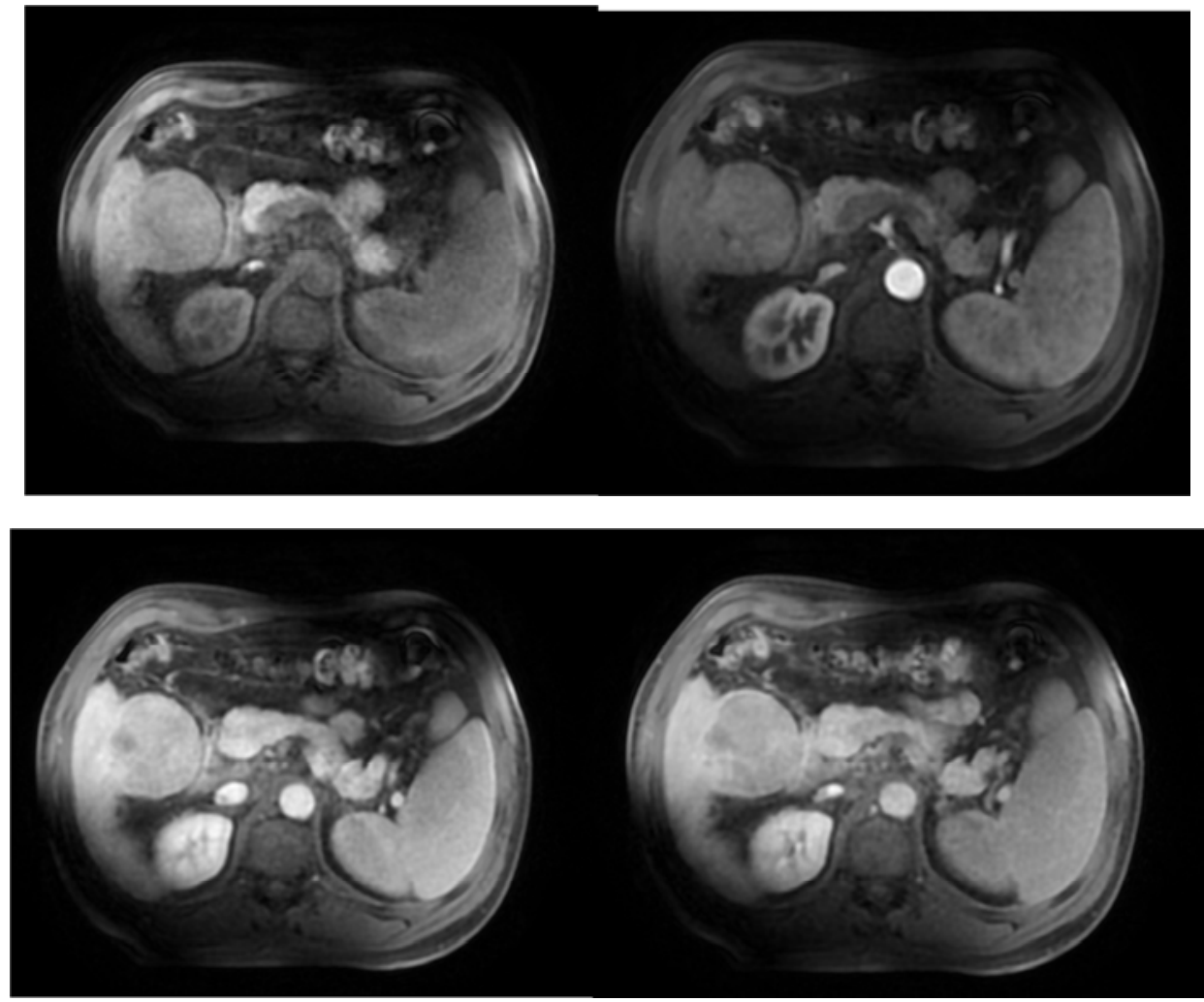

Figure 2. Dynamic MRI shows segment V exophytic HCC mass measuring $6.8 x 6.8 \mathrm{~cm}$. 

Injection (PEI) Vs. (TACE) for Unresectable Hepatocellular Carcinoma

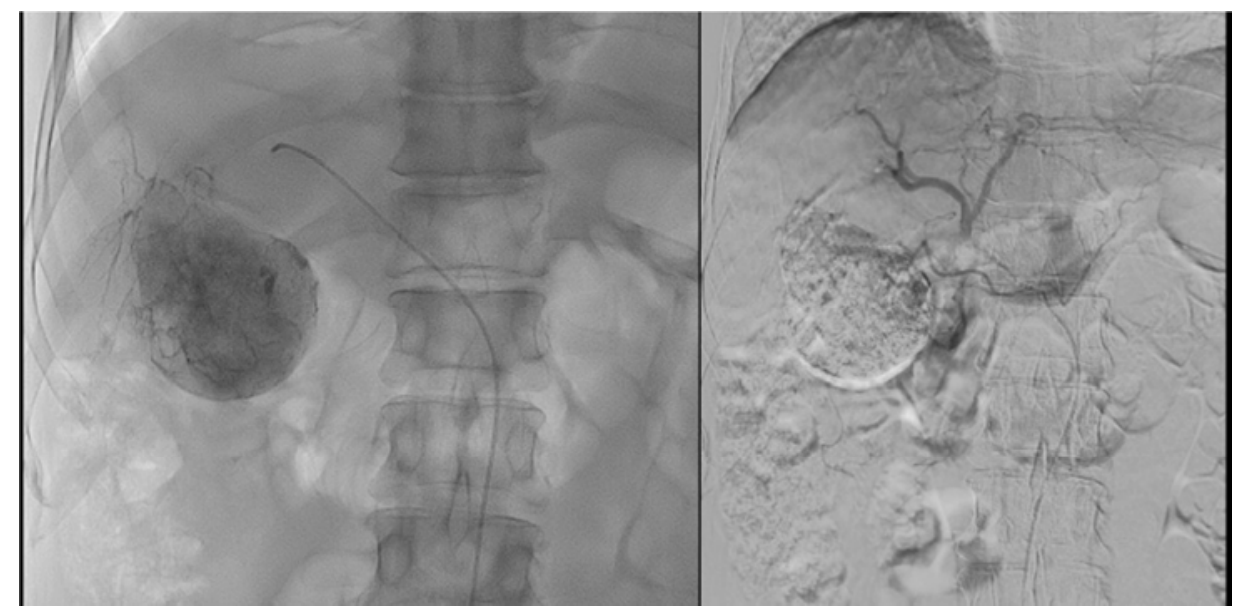

Figure 3. Digital subtraction angiogram showing vascularization within the HCC mass, postembolization showed accumulation of lipidol in the tumor bed.

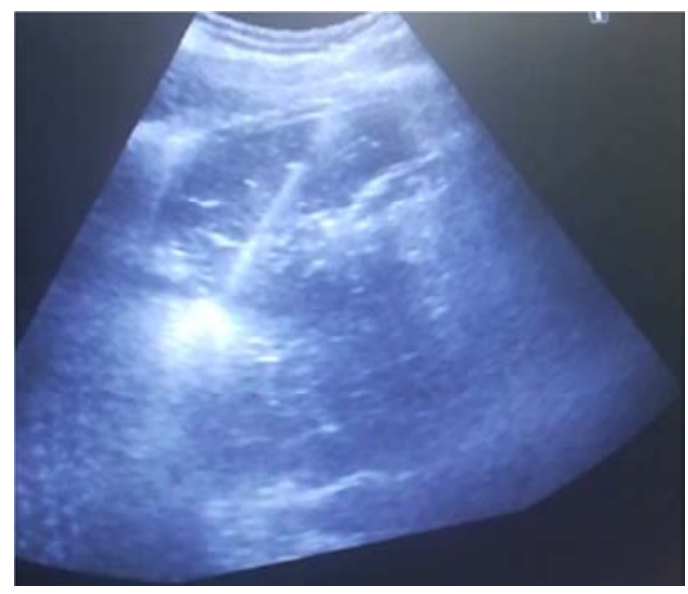

Figure 4. Real time ultrasound of percutaneous $6 \mathrm{~cm}$ alcohol injection via $18 G$ Chiba needle.

Follow up at one month:

(a)

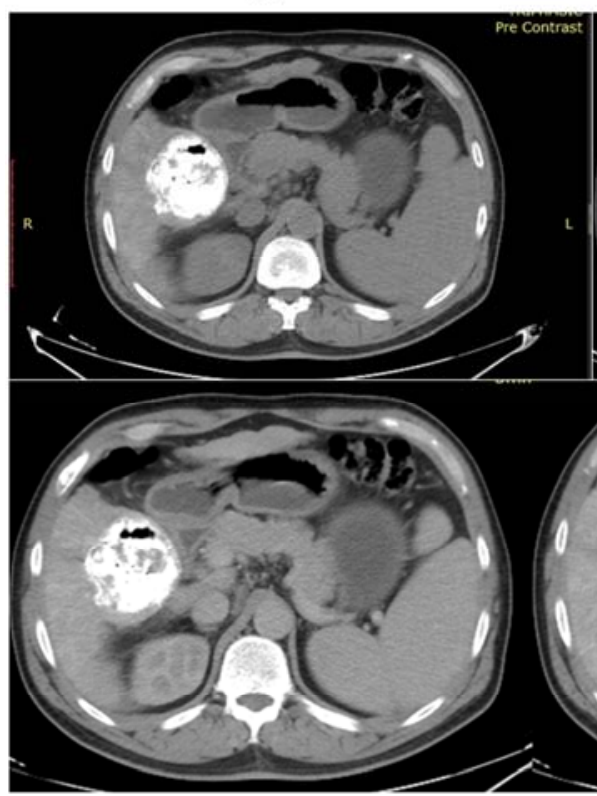

(c) (b)

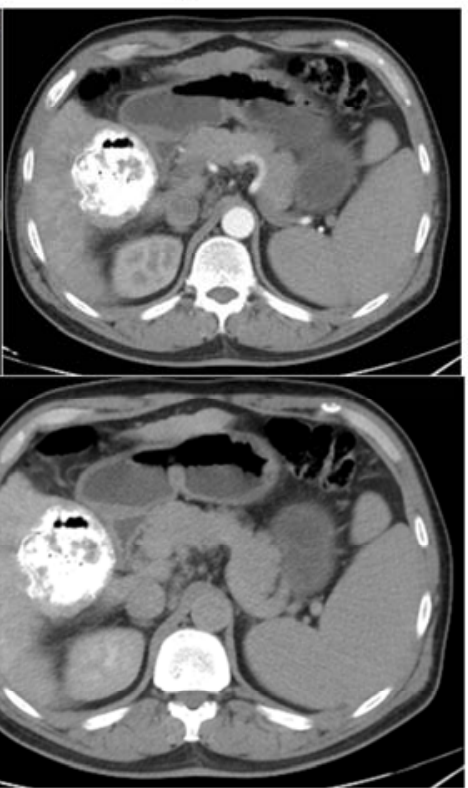

(d)

Figure 5. Triphasic CT (a)--Non contrast,(b)--arterial phase, (c)--venous phase,(d)--delayed phase showing total resolution of the mass with no residual activity, the same appearance after 3 months. 
Follow up after 6 months:

(a)
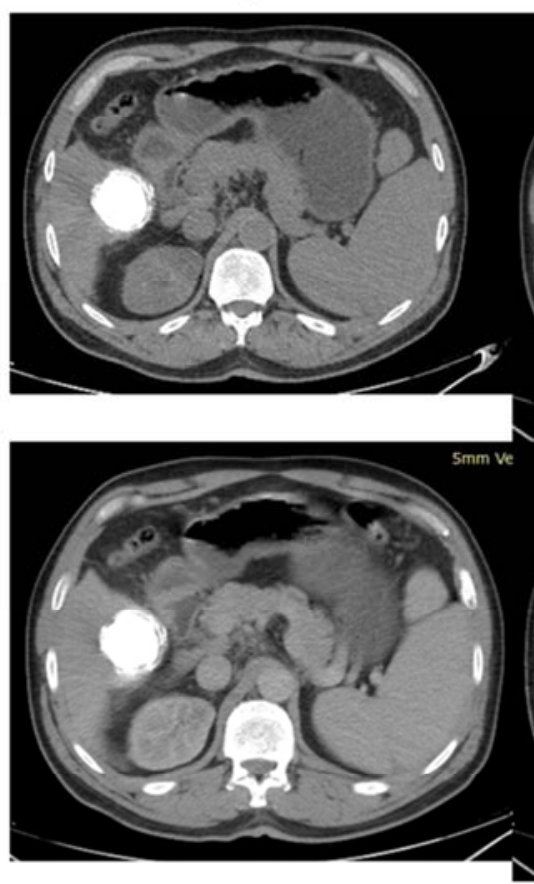

(c) (b)
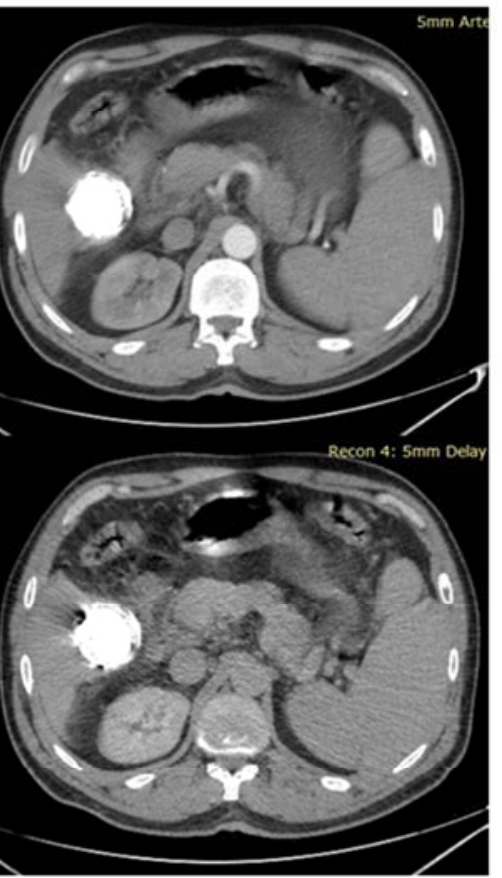

(d)

Figure 6. Triphasic CT, (a)--Non contrast,(b)--arterial phase, (c)--venous phase,(d)--delayed phase showing no residual activity within the mass with decrease in its size.

\subsection{Case 2}

Clinical picture:

Male patient aged 55 years old presented by right hypochondial pain

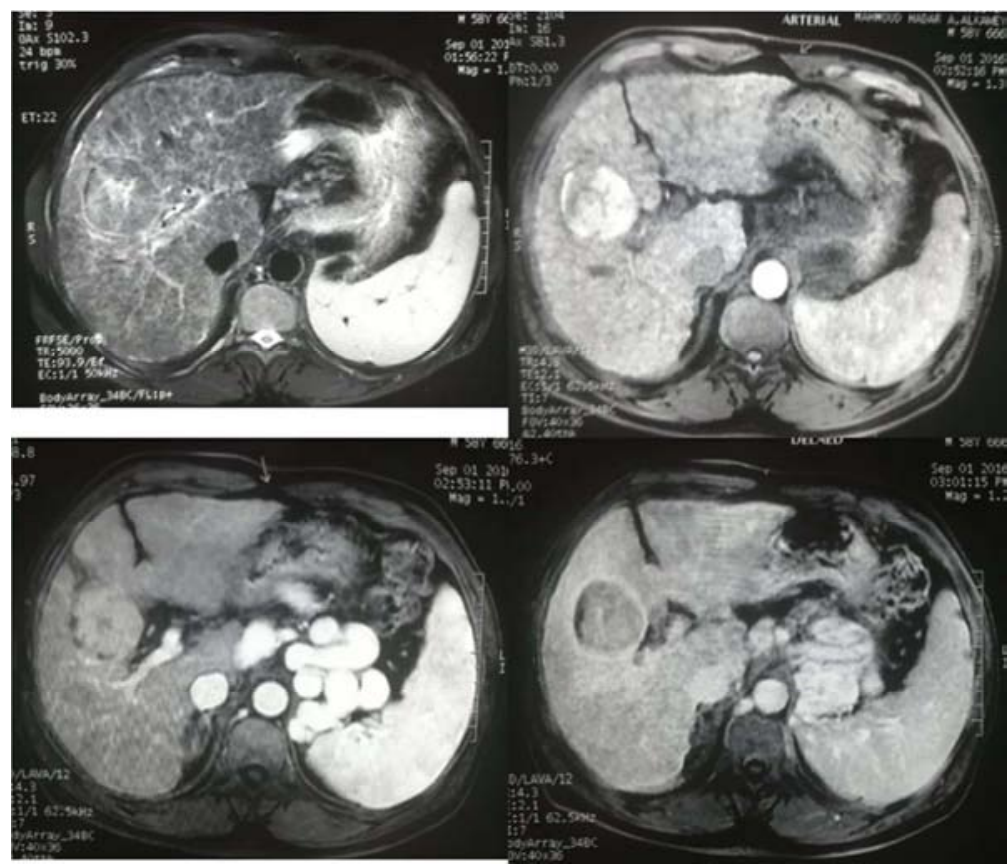

Figure 7. Dynamic MRI study showing cirrhotic liver with hepatic mass at segment VIII showing heterogenous enhancement in the arterial phase and total washout in the delayed phase, splenomegaly and splenic hilar varices.

Follow up at one month 


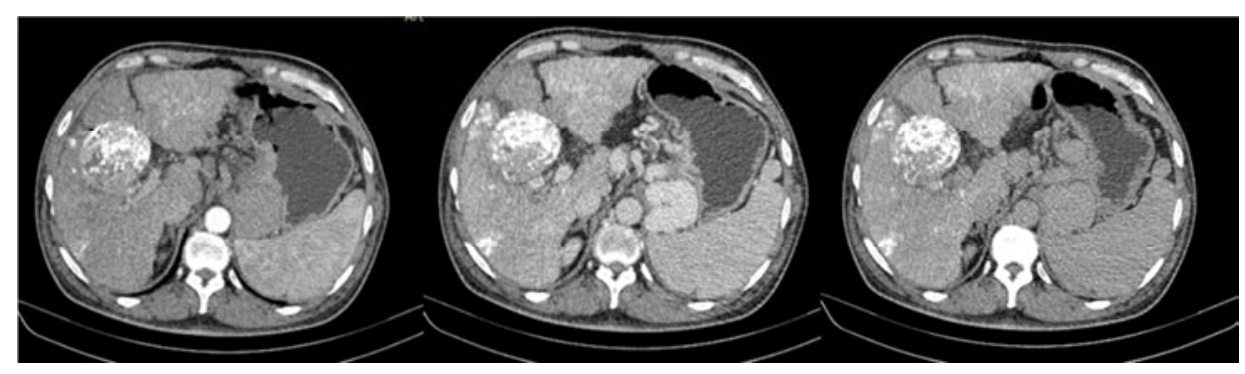

Figure 8. Triphasic CT showing insufficient lipidol retention within the mass with residual enhancement in arterial and washout in portovenous and delayed phases.

\section{Follow up after second TACE session}

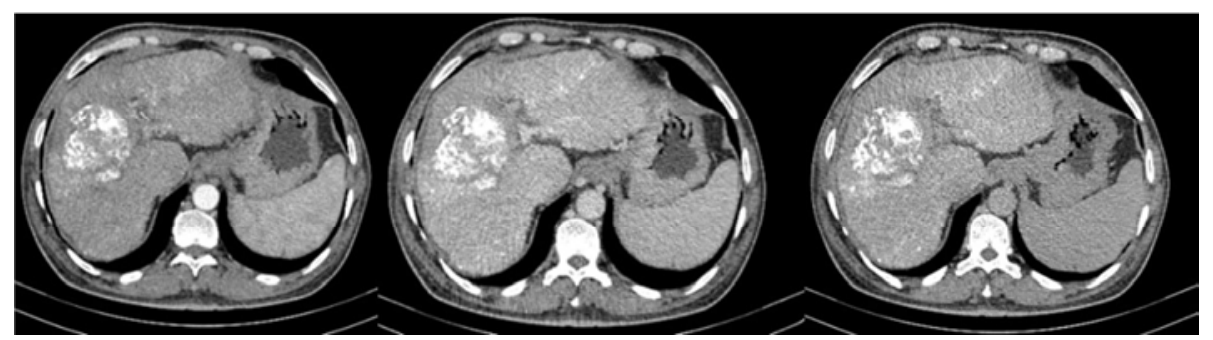

Figure 9. Triphasic CT showing enlargement of the mass (6.8x6) with insufficient lipidol retention within the mass with residual enhancement in arterial and washout in delayed phase.

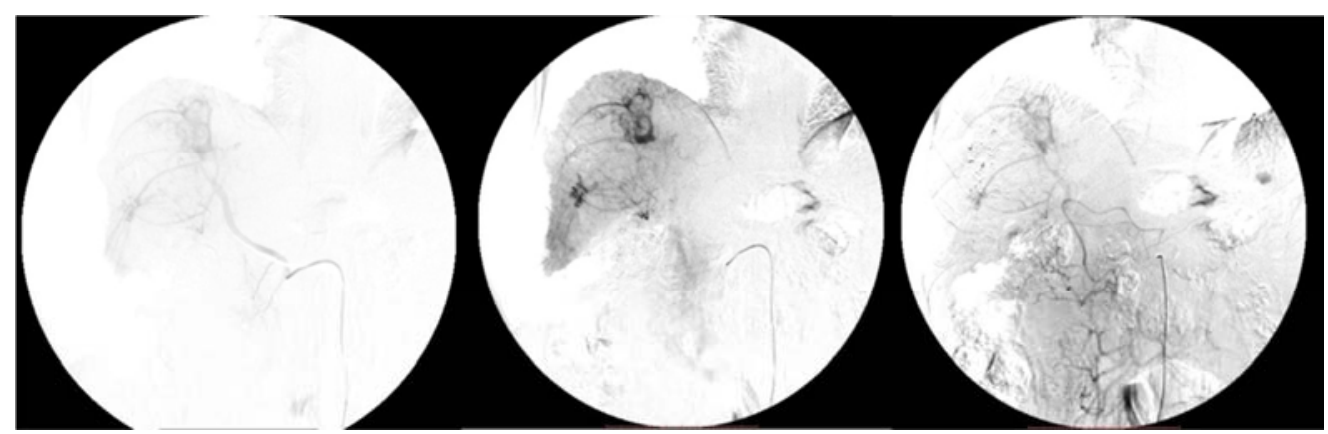

Figure 10. Third TACE Digital subtraction angiogram showing vascularization within the peripheral part of the mass.

Follow up after third TACE:

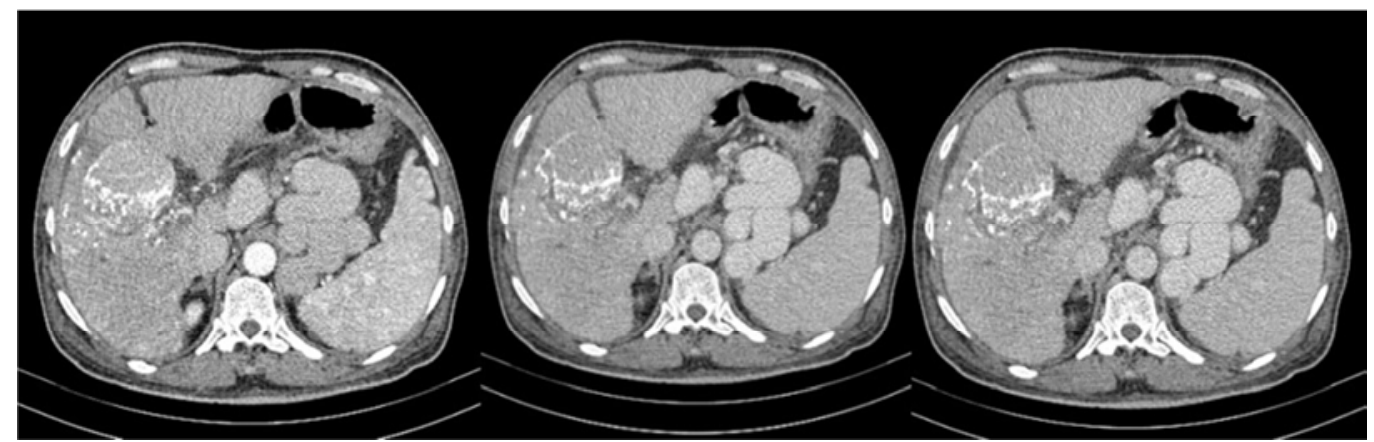

Figure 11. Triphasic CT showing no evidence of residual activity within the mass.

\section{Discussion}

We aimed in this study to compare the combined Transcatheter arterial chemoembolization(TACE) with percutaneous ethanol injection (PEI) against the technique of TACE alone in patients with unresectable HCC. Therefore, 50 patients who met our inclusion criteria were included and randomly divided into 2 groups.

$92 \%$ of our study population were male versus $8 \%$ female. This male predominance in HCC has been reported in many previous studies and was related to both behavioral factors like smoking, alcohol consumption, increase vulnerability to hepatitis $\mathrm{C}$ virus and hepatitis $\mathrm{B}$ virus infection as well as biological factors such as protective effect of estrogen against 
HCC(decreases IL-6 mediated hepatic inflammation) [11, $12]$.

Among our patients, abdominal pain was the most frequent presentation of HCC. No patients presented with symptoms suggesting bile duct invasion (cholangitis or obstructive jaundice).

Many previous studies supported the hypothesis that the prognosis of HCC with bile duct invasion can be worse than HCC without invasion $[13,14]$. On the other hand, Satoh et al [15] and Shiomi et al.[16] also reported that prognosis of HCC with bile duct invasion is similar to that of patients without bile duct thrombus.

Sixty two $(62 \%)$ of our study population was Child A versus $38 \%$ Child B. The Child score is a simple and widely used grading system for liver function [17]. However, there are many drawbacks including inter laboratory variations, day-to-day fluctuations in the key parameters and the subjective nature of the clinical grading of chronic liver disease [18].

The commonest site of focal lesion in group 1 was in hepatic segment VII while in group 2 was segment VIII. However, tumor location in our study was not linked to outcome of intervention treatment.

Interestingly, Miki et al. [19] reported a significant difference in TACE efficacy is found only in the right lobe and medial segment and not in the lateral segment. They explained that by 2 phenomena First, thin anastomosis branches often present between the right hepatic and the middle hepatic arteries [20]. Second, cirrhotic livers associated with all etiologies demonstrate atrophy of the right lobe and medial segment as well as hypertrophy of the caudate lobe and lateral segment [21]. That significant difference between the location of HCC and the efficacy of TACE only in the Child-Pugh grade A patients. In ChildPugh grade B patients, there was no relationship between any nodules, even in the right lobe and medial segment. These results suggested that hepatic hemodynamics may change depending on cirrhotic liver status [22].

In this study, we categorize AFP levels, either higher than $200 \mathrm{ng} / \mathrm{mL}$, less than $100 \mathrm{ng} / \mathrm{ml}$, or between $100 \mathrm{ng} / \mathrm{m}$ and $200 \mathrm{ng} / \mathrm{ml}$. There was a statistically significant reduction in alpha-feto protein level at 3 months post interventional in group I and in both groups at 6 months.

In 2005, Chen et al. first introduced the concept of 'AFP response'. AFP response was defined as a $50 \%$ or greater reduction of AFP levels for 4 or more weeks during treatment. They reported that serum AFP response was independent prognostic factor for both progression-free survival and overall survival, whereas radiographic response was not [23]. Other definitions of AFP response or AFP change were applied with different cut-offs of the reduction of AFP after treatment. For example, AFP response or change were defined as AFP reduction greater than 20\%, $46 \%$ and $50 \%$ [24-28]. Therefore, a universal definition of AFP response or AFP change to predict the prognosis after treatment for various treatment modalities and different tumor stage may be impossible.
Decreases in serum AFP level after locoregional therapy can predict the tumor response and survival [29]. Although $10 \%$ to $30 \%$ of patients with $\mathrm{HCC}$ are negative for AFP expression

Post embolization syndrome (fever, nausea, vomiting, anorexia and right hypochondrial pain) was the most common complication reported among our patients followed by renal impairment. Although we used MRI for follow up of those patients with renal impairment, $60 \%$ of them required later schedules to continue their treatment. Therefore, their outcome was affected.

Fortunately, no major complications occurred in either groups. Complications of TACE or alcohol injection might liver abscess, liver rupture, biliary tract injury, necrotizing pancreatitis, cerebral lipiodol embolism [30-35].

Regarding to overall survival, we did not find significant difference between both groups at the end of follow up period (6 months). also, mortality occurred only in Child B class patients in either group. This emphasize the importance of liver status prior to procedure selection.

Similar but not typical results obtained by Gerhild Becker who conducted a prospective randomized control trial [36] and showed that TACE plus PEI did not significantly improve the overall survival for HCC patients. However, the survival benefits was observed in patients with HCC Okuda stage I under combination therapy, indicating that only patients with good liver function could gain a better survival benefit from the combination therapy.

A possible explanation could be repeated procedures of TACE or PEI would damage non-cancerous hepatocyte functions and may have potential impact on the therapeutic effect [37]

On the other hand, Ni Jiayan et al [38] conducted metaanalysis to assess the effectiveness of the combination of TACE and percutaneous ablation (including PEI, radiofrequency ablation) with that of monotherapy in the treatment of HCC. They found that TACE plus percutaneous ablation had beneficial effects on 1- and 3-year overall survival rate (OR1-year $=4.61,95 \%$ CI: 2.26, $9.42 ; \mathrm{P}<0.0001 ; \quad$ OR3-year $=2.79,95 \% \quad \mathrm{CI}: \quad 1.69,4.61$; $\mathrm{P}<0.0001)$ and 3 -year recurrence-free survival $(\mathrm{OR}=3.0$, 95\% CI: 1.75, 5.13; $\mathrm{P}<0.0001)$.

Another Chinese meta-analysis from 19 randomized controlled trials [39] demonstrated that the combined therapy of TACE and PEI significantly improved the survival rate at 1, 2, 3-year, and decreased the local tumor recurrence rate, AFP level and tumor size. The pooled results for survival rate at 1, 2, 3-year were 1.24 (95\% CI: 1.17-1.31, P = 0.000), 1.64 (95\% CI: 1.44-1.87, P = 0.000) and 2.27 (95\% CI: 1.93-2.67, $\mathrm{P}=0.000)$, respectively, and for local tumor recurrence rate was 0.53 (95\% CI: 0.29-0.98). They concluded the therapeutic benefits of TACE plus PEI for unresectable HCC patients in terms of survival and local tumor recurrence.

Similarly in this study complete resolution of HCC mass was achieved in $60 \%$ in group I (received combined TACE and alcohol) versus $52 \%$ in group II (received TACE only). Although the duration of follow up was short, we could 
assess other important factors such as local, other segment recurrence and distant metastasis.

Tumor recurrence is the leading risk factor that affects the prognosis of HCC patients.

When comparing both groups in terms of recurrence, group I has lower local recurrence rate than group II. However, group II has lower distant recurrence rate. Distance recurrence refers to other segment recurrence (which was higher in group received combined therapy) and extrahepatic metastasis (which was higher in monotherapy group). It might be unfair to include distant recurrence with its 2 arms as an item for comparison between both groups. as patients already have liver cirrhosis and liable for HCC development. Moreover, both modalities are approved as palliative treatment.

Another important player in the game against HCC is tumor size. Regarding to TACE, it is often difficult to achieve complete necrosis of the target tumor by TACE once, because HCC often shows intracapsular or extracapsular invasion and viable tumor cells remain after TACE (Germani et al., 2010) [40]. Therefore, TACE needs to be repeated to achieve better result. Ebied et al.[41] reported the response to TACE as inversely proportional to tumor size (response in $70 \%$ of $\mathrm{HCCs}<3 \mathrm{~cm}$, in $56 \%$ of HCCs 3 to $5 \mathrm{~cm}$, and in $43 \%$ of HCCs $>10 \mathrm{~cm}$ ). Recently, Golfieri et al. [42] reported that HCCs $\leq 5 \mathrm{~cm}$ were the best responders to superselective TACE; nodules $\leq 2 \mathrm{~cm}$ and nodules between 2.1 and $5 \mathrm{~cm}$ had similar and high Cure rate rates after the first super-selective TACE $(68 \%$ and $64 \%)$, whereas in $\mathrm{HCCs}>5 \mathrm{~cm}, \mathrm{CR}$ rate significantly decreased (25\%).

On the other hand, In PEI, the injection of absolute alcohol into the tumor causes cellular dehydration, coagulation necrosis, and vascular thrombosis within the HCC (Bruix et al., 2001). While complete necrosis of the target HCC can be obtained in most patients with small HCC tumors treated by RFA or PEI alone, a similar result can be obtained in only about $40 \%$ of the patients treated by TACE alone (Riaz et al., 2010). However, several factors limit the effect of both RFA and PEI, such as tumor consistency, tumor vascularization, and tumor size. Therefore, RFA and PEI are generally indicated for tumors fulfilling the Milan criteria, defined as the presence of a tumor not exceeding $5 \mathrm{~cm}$ in diameter in patients with a single HCC or presence of not more than three tumor nodules, with none exceeding $3 \mathrm{~cm}$ in diameter. Therefore, the rationale for combining TACE with PEI lies in the fact that after TACE, the tumor consistency is markedly softened and the intra-tumoral septa are usually disrupted, allowing enhanced ethanol diffusion within or easier thermal ablation of the tumor (Wilson et al., 2012).

In our study. Cost-effectiveness is another issue that has acquired importance over the last years. Large referral centers have explored this topic recently, as an attempt to optimize economic resources involved in HCC treatment 20.

In this work, it is noticeable that complete resolution of the HCC mass occurs earlier in group I than group II $(69.5 \%$ after first session versus $13.02 \%$ ). Therefore, combined treatment could help in saving time and resources.
Our study has some limitations. First, short duration of follow up. Second, relatively small number of study population third, no patients with HCC mass at caudate lobe which is an area of more debate.

\section{Conclusion}

From this study we could conclude that there are many palliative options for treatment of unrestecable HCC.The combination between TACE and percutaneous ethanol injection does not carry significant additional side effects. Also, the combined treatment does not significantly decrease the incidence of local or distant metastasis of HCC.

The combination of repeated sessions of TACE and per cutenous ethanol injections for treatment of unresctable HCC offer better and rapid response compared to repeated sessions of TACE alone as well as saving time and cost.

\section{References}

[1] Jemal A, Bray F, Center MM, et al. (2011) Global cancer statistics. CA Cancer J Clin; 61: 69-90.

[2] Liovet JM and Bruix (2003) J. systematic review of randomized trials for unresectable hepatocellular carcinoma: chemoembolization improves survival. Heaptology; 37: 429-42.

[3] Kudo M. Japan's Successful Model of Nationwide Hepatocellular Carcinoma Surveillance, Highlighting the Urgent Need for Global Surveillance. Liver Cancer, in press.

[4] Kim DY and Han KH (2012). Epidemiology and surveillance of hepatocellular carcinoma. Liver Cancer 2012; 1: 2-14.

[5] Bruix J and Llovet JM. (2002) Prognostic prediction and treatment strategy in hepatocellular carcinoma. Hepatology; 35: 519-24.

[6] Llovet JM, Burroughs A and Bruix J. (2003) Hepatocellular carcinoma. Lancet; 362: 1907-17.

[7] Mondazzi L, Bottelli R, Brambilla G, et al. (1994) Transarterial oily chemoembolization for the treatment of hepatocellular carcinoma: a multivariate analysis of prognostic factors. Hepatology; 19: 1115-1123.

[8] Shiina S, Teratani T, Obi S, et al. (2005) A randomized controlled trial of radiofrequency ablation with ethanol injection for small hepatocellular carcinoma. Gastroenterology; 129: 122-30.

[9] Brunello F, Veltri A, Carucci P, et al. (2008) Radiofrequency ablation versus ethanol injection for early hepatocellular carcinoma: a randomized controlled trial. Scand J Gastroenterol; 43: 727-35.

[10] Bartolozzi C, Lencioni R, Caramella D, et al. (1995) Treatment of large HCC: transcatheter arterial chemoembolization combined with percutaneous ethanol injection versus repeated transcatheter arterial chemoembolization. Radiology; 197: 812-8.

[11] Altekruse SF, Henley SJ, Cucinelli JE, et-al. (2014): Changing hepatocellular carcinoma incidence and liver cancer mortality rates in the United States. Am J Gastroenterol; 109: 542-53. 
[12] Iyer JK, Kalra M, Kaul A, et al. (2017): Estrogen receptor expression in chronic hepatitis $\mathrm{C}$ and hepatocellular carcinoma pathogenesis. World J Gastroenterol; 23: 6802-16.

[13] Noda T, Nagano H, Tomimaru Y, Murakami M, Wada H, Kobayashi S, et al.(2011) Prognosis of hepatocellular carcinoma with biliary tumor thrombi after liver surgery. Surgery.; 149: 371-377.

[14] Xiangji L, Weifeng T, Bin Y, Chen L, Xiaoqing J, Baihe Z, et al. Surgery of hepatocellular carcinoma complicated with cancer thrombi in bile duct: efficacy for criteria for different therapy modalities. Langenbecks Arch Surg. 2009; 394: 10331039.

[15] Satoh S, Ikai I, Honda G, et al. Clinicopathologic evaluation of hepatocellular carcinoma with bile duct thrombi. Surgery. 2000; 128: 779-783.

[16] Shiomi M, Kamiya J, Nagino M, et al. (2011): Hepatocellular carcinoma with biliary tumor thrombi: aggressive operative approach after appropriate preoperative management. Surgery.; 129: 692-698.

[17] Subramaniam S, Kelley RK, Venook AP. (2013): A review of hepatocellular carcinoma (HCC) staging systems. Chin ClinOncol; 2: 33 (PMID: 25841912 DOI: 10.3978/j.issn.23043865.2013.07.05).

[18] Botta F, Giannini E, Romagnoli P, et al. (2003): scoring system is useful for predicting prognosis in patients with liver cirrhosis and is correlated with residual liver function: a European study. Gut; 52: 134-139 (PMID: 12477775).

[19] Miki I, Murata S, Uchiyama F, et al. (2017): Evaluation of the relationship between hepatocellular carcinoma location and transarterial chemoembolization efficacy. World J Gastroenterol; 23(35): 6437-6447.

[20] Hiramatsu K, Koda E, Mori M, Isobe Y. (1982): X-ray Anatomy of the Abdominal Vascular System. Tokyo: IgakuShoin; 63-81.

[21] Niggemann P, Murata S, Naito Z, et al. (2004): A comparative study of the microcirculatory changes in the developing liver cirrhosis between the central and peripheral parts of the main lobe in mice. Hepatol Res.; 28: 41-48.

[22] Tamada T, Ito K, Higaki A, et al. (2011): Gd-EOB-DTPAenhanced MR imaging evaluation of hepatic enhancement effects in normal and cirrhotic livers. Eur J Radiol.; 80: e311e316.

[23] Chen LT, Liu TW, Chao Y, et al. (2005): alpha-fetoprotein response predicts survival benefits of thalidomide in advanced hepatocellular carcinoma. Aliment Pharmacol Ther.; 22: 217226.

[24] Memon K, Kulik L, Lewandowski RJ, et al. (2012): Alphafetoprotein response correlates with EASL response and survival in solitary hepatocellular carcinoma treated with transarterial therapies: a subgroup analysis. J Hepatol.; 56: $1112-1120$

[25] Lee S, Kim BK, Kim SU, et al. (2015): Early alphafetoprotein response predicts survival in patients with advanced hepatocellular carcinoma treated with sorafenib. J Hepatocell Carcinoma.; 2: 39-47.

[26] Kao WY, Chiou YY, Hung HH, et al. (2012): Serum alphafetoprotein response can predict prognosis in hepatocellular carcinoma patients undergoing radiofrequency ablation therapy. Clin Radiol.; 67: 429-436.

[27] Shao YY, Lin ZZ, Hsu C, et al (2010): Early alpha-fetoprotein response predicts treatment efficacy of antiangiogenic systemic therapy in patients with advanced hepatocellular carcinoma. Cancer.; 116: 4590-4596.

[28] Liu L, Zhao Y, Jia J, et al. (2016): The prognostic value of alpha-fetoprotein response for advanced-stage hepatocellular carcinoma treated with sorafenib combined with transarterial chemoembolization. Sci Rep.; 6: 19851.

[29] Riaz A, Ryu RK, Kulik LM, et al. (2009): Alpha-fetoprotein response after locoregional therapy for hepatocellular carcinoma: oncologic marker of radiologic response, progression, and survival. J Clin Oncol.; 27: 5734-5742. doi: 10.1200/JCO.2009.23.1282.

[30] Bae SI, Yeon JE, Lee JM, et al. (2012): A case of necrotizing pancreatitis subsequent to transcatheter arterial chemoembolization in a patient with hepatocellular carcinoma. ClinMolHepatol; 18: 321-5.

[31] Miyayama S, Yamashiro M, Okuda M, et al. (2010): Main bile duct stricture occurring after transcatheter arterial chemoembolization for hepatocellular carcinoma. Cardiovasc Intervent Radiol; 33: 1168-79.

[32] Chu HJ, Lee CW, Yeh SJ, et al. (2015): Cerebral lipiodol embolism in hepatocellular carcinoma patients treated with transarterial embolization/chemoembolization. PLoS One; 10: e0129367.

[33] Toro A, Bertino G, Arcerito MC, et al. (2015): A lethal complication after transarterial chemoembolization with drugeluting beads for hepatocellular carcinoma. Case Rep Surg; 2015: 873601 .

[34] Pietrosi G, Miraglia R, Luca A, et al. (2009): Arterial chemoembolization/embolization and early complications after hepatocellular carcinoma treatment: a safe standardized protocol in selected patients with Child class A and B cirrhosis. J VascInterv Radiol; 20: 896-902.

[35] Jia Z, Tian F and Jiang G. (2013): Ruptured hepatic carcinoma after transcatheter arterial chemoembolization. CurrTher Res ClinExp; 74: 41-3.

[36] Becker G, Soezgen T, Olschewski M, e al. (2005): Combined TACE and PEI for palliative treatment of unresectable hepatocellular carcinoma. World J Gastroenterol; 11: 6104-9.

[37] Chua TC, Liauw W, Saxena A, et al. (2009): Systematic review of neoadjuvanttransarterial chemoembolization for resectable hepatocellular carcinoma. Liver Int; 30: 166-74.

[38] Jia-yan Ni, Shan-shan Liu, Ni JY, et al. (2013): Transarterial chemoembolization combined with percutaneous radiofrequency ablation versus TACE and PRFA monotherapy in the treatment for hepatocellular carcinoma: a meta-analysis. J Cancer Res Clin Oncol; 139: 653-659.

[39] Yang Fu1, Xu Zhao2, Qiang Yun3, et al: Transarterial chemoembolization (TACE) plus percutaneous ethanol injection (PEI) for thetreatment of unresectable hepatocellular carcinoma: a meta-analysis of randomized controlled trials.

[40] Germani G, Pleguezuelo M, Gurusamy, et al (2010). Clinical outcomes of radiofrequency ablation, percutaneous alcohol and acetic acid injection for hepatocellular: a meta-analysis. J Hepatol, 52, 380-87. 
[41] Ebied OM, Federle MP, Carr BI, et al. (2003): Evaluation of responses to chemoembolization in patients with unresectable hepatocellular carcinoma. Cancer.; 97: 1042-1050. doi: $10.1002 /$ cncr.11111.
[42] Golfieri R, Renzulli M, Mosconi C, et al. (2013): Hepatocellular carcinoma responding to superselective transarterial chemoembolization: an issue of nodule dimension? J Vasc Interv Radiol.; 24: 509-517. doi: 10.1016/j.jvir.2012.12.013. 